\title{
Empirical Investigation into the Determinants of Public Debts in Africa: New Insights Using a Panel Bayesian Model Averaging Approach
}

Nimonka Bayale ( $\square$ nimonka.bayale@un.org )

Macroeconomic and Governance Division (MGD), United Nations Economic Commission for Africa (UNECA)

\section{Research}

Keywords: Bayesian model averaging, Panel data, Public debt determinants, Africa

Posted Date: June 18th, 2020

DOI: https://doi.org/10.21203/rs.3.rs-35686/v1

License: (c) (i) This work is licensed under a Creative Commons Attribution 4.0 International License.

Read Full License 


\title{
Empirical Investigation into the Determinants of Public Debts in Africa: New Insights Using a Panel Bayesian Model Averaging Approach
}

\author{
Nimonka Bayale ${ }^{1,2}$ \\ ${ }^{1}$ Macroeconomic and Governance Division (MGD), United Nations Economic Commission \\ for Africa (UNECA), Addis Ababa, Ethiopia. \\ E-mail : nimonka.bayale@,un.org \\ ${ }^{2}$ Department of Economics, University of Kara (UK), Kara, Togo. \\ E-mail : richard_bayale15@yahoo.fr
}

\begin{abstract}
The determinants of public indebtedness in developing countries is still generating a lot of interest among academics and policy makers. This paper introduces model uncertainty into the empirical study on the determinants of public debt at continental level. This is done by adopting a Bayesian model averaging approach applied to data of 51 African countries spanning from 1990 to 2018. Our results suggest that, among the set of twenty-seven (27) regressors considered in the baseline model, those reflecting international financial and institutional conditions as well as internal economic prospects tend to receive high posterior inclusion probabilities. These findings are robust to changes in the model specification, the inclusion of economic crises and geographical heterogeneities of the continent.
\end{abstract}

Keywords: Bayesian model averaging, Panel data, Public debt determinants, Africa JEL Classification : C11 ; C23 ; F34 ; N27. 


\title{
Empirical Investigation into the Determinants of Public Debts in Africa: New Insights Using a Panel Bayesian Model Averaging Approach
}

\begin{abstract}
The determinants of public indebtedness in developing countries is still generating a lot of interest among academics and policy makers. This paper introduces model uncertainty into the empirical study on the determinants of public debt at continental level. This is done by adopting a Bayesian model averaging approach applied to data of 51 African countries spanning from 1990 to 2018. Our results suggest that, among the set of twenty-seven (27) regressors considered in the baseline model, those reflecting international financial and institutional conditions as well as internal economic prospects tend to receive high posterior inclusion probabilities. These findings are robust to changes in the model specification, the inclusion of economic crises and geographical heterogeneities of the continent.
\end{abstract}

Keywords: Bayesian model averaging, Panel data, Public debt determinants, Africa JEL Classification : C11; C23 ; F34 ; N27. 


\section{Introduction}

Since the onset of the debt crises in the early 1970s and 1980s which affected most developing and transition economies, there has been an upsurge in the empirical analysis of the determinants of public debt (IMF, 2019; World Bank, 2019; ECA, 2019; Easterly, 2002). The economic literature has identified several factors both external and internal that can influence public debt (Calderón and Zeufack, 2020; Bayale et al., 2020; Atta-Mensah and Ibrahim, 2020; Fatás et al., 2019; Sadik-Zada and Gatto, 2019; Chiminya and Nicolaidou, 2015; Forslund et al., 2011). Externally, adverse global developments such as such as global financial crises, oil price shocks, high interest rates, recessions in industrial and developed countries and weak commodity prices (specifically raw materials) are identified to be the main drivers of public debt accumulation (Atta-Mensah and Ibrahim, 2020; Fatás et al., 2019; AfDB, 2018; Chiminya and Nicolaidou, 2015, Easterly, 2002). On the domestic front, macroeconomic policies have been blamed such as fiscal irresponsibility, exchange rate misalignment, policies that deter saving (negative real interest rates for instance) and the institutional framework (Calderón and Zeufack, 2020; IMF, 2019; World Bank, 2019; ECA, 2019; AfDB, 2018; Forslund et al., 2011).

Beyond studies cited above, Bayale et al. (2020), Fatás et al. (2019), Bohn and Veiga (2019), Potrafke (2018) and Alesina and Passalacqua (2016) have found that even if factors mentioned can explain some of the increases in public debt in recent decades, they cannot account for all of the observed changes. So, the political factors (electoral cycles) may also generate different incentives to borrow. They are a major cause of overborrowing though budgetary institutions and fiscal rules can play a role in mitigating governments' tendencies to overborrow. Most of these studies applied a wide array of estimation methods on large sample sizes and long periods of studies. This implies that, although it is important to unveil the main causes of public debt, there is no clear consensus on the determinants of public debt in the literature. For instance, Zdravković (2019) Ksantini (2016) and Karazijienè (2015) provided an overview and critical discussion of the early evidence about the sources of the debt accumulation, reaching no conclusive results.

A theoretical foundation for the hypothesis that economic grievances generate public debt, based on the rational-choice theory and without dismissing non-economic factors, can be found in the seminal papers of Fatás et al. (2019), Aybarç (2019), Alesina and Passalacqua (2016) and Bilan (2016). These authors suggest that the lack of empirical consensus on the causes of debt has to do with its heterogeneity and that its link with the economy needs to be further investigated, especially in developing countries.

When analyzing and explaining the trajectory of Africa's debt levels over the past decades, Atta-Mensah and Ibrahim (2020) have applied a statistical analysis and found that the interest rate-growth differential is the main drivers of overall debt dynamics in African economies. By focusing on the motives to borrow, Fatás et al. (2019) based on exploratory analysis and established that intertemporal tax-smoothing, fiscal stimulus and asset management can explain some of the increases in public debt in recent years. Sadic-Zada and Gatto (2019) investigated into the major drivers of the public debt growth in 184 countries. The authors 
applied panel data approach. Their findings have shown that oil abundance, economic growth rate, the share of mineral rent in the total revenue, interest rate payments for foreign borrowings, and being a developing country have statistically significant impact on the growth of the public debt, whereas defense spending, unemployment rate, and inflation rate do not have a statistically significant positive impact on the public debt rate. According to Chiminya and Nicolaidou (2015) who investigated into the determinants of External debt in Sub Saharan Africa using pooled OLS and fixed effects, countries that received debt relief seem to accumulate less debt in comparison to those that did not receive debt relief. Their findings also highlighted the importance of economic activity in reducing debt in the region. Economies that are more open to international trade reduce their debt burden. Forslund et al., (2011) analyzed the determinants of the composition of public debt in developing and emerging market countries. Authors have found a weak correlation between inflation and the composition of public debt. For Bayale et al. (2020), election events are positively correlated to public debt in Africa when the GMM estimator is applied. In these all studies, the majority of the variables suggested in the literature are not taken into account.

Motivated by the lack of consensus on the determinants of public debt, we contribute to the literature by introducing model uncertainty into this context through a Bayesian model averaging (BMA) approach (Moral-Benito, 2015; Rafter et al., 2017; Okafor, 2017; Clyde, 2018). By proceeding in this way, we are able to simultaneously deal with model selection, estimation and inference. In a nutshell, BMA assigns a prior probability to a set of models and updates it according to the data. The posterior model probabilities are later averaged and used to construct posterior inclusion probabilities (PIP) for the candidate regressors (SansoNavarro and Vera-Cabello (2018). Our aim is to investigate into the determinants of public debts in Africa using this new sound methodological approach. Our empirical analysis controls the characteristics (homogeneity or heterogeneity) of our data on public debt in Africa by implementing the BMA in a linear panel data model framework. The first contribution of the paper is therefore linked to the methodological approach used. Second, we contribute to the existing literature by providing a more nuanced and in-depth details on the debt dynamics determinants in Africa. Third, relying on the findings this study proffers useful, relevant and practical recommendations for policy.

Our analyses suggest that official development assistance, trade openness, military expenditure, real interest rate, debt-service paid, the domestic credit provided by financial sector, government stability index, political regime type, real effective exchange rate, budget balance and mobile cellular subscriptions (which captures infrastructure indicator in our study) are the main determinants of public debt accumulation in Africa. The remainder of this paper is organized as follows. Section 2 presents data sources and variables. In section 3, we present the empirical strategy adopted in this paper. We present results from our empirical analysis in section 4. Finally, Section 5 concludes, establishes policy recommendations and proposes avenues for future research. 


\section{Data sources and variables}

In this paper, we are following Fatás et al. (2019), Alesina and Passalacqua (2016) and Forslund et al. (2011), who identified broad theoretical families linking debt with socioeconomic, political and demographic factors. In this regard, IMF, World Bank, SIPRI, NELDA and ICRG databases have been used. So, we then extracted data on public debt from the World Economic Outlook (WEO) database of the International Monetary Fund (IMF). It contains selected macroeconomic data series such as budget balance, inflation, real effective exchange rate and real interest rate. It was reasonable to extract the data on this first group of variables from there because the IMF, whose mission is to ensure the stability of the international monetary system, has data closer to that of countries (national accounts) on these variables (IMF, 2019). Due to the lack of data on some variables, our sample is made up of 51 African countries and covers the period 1990-2018 (see the Appendix I). A description of the whole set of regressors considered in the baseline empirical analysis can be found in Table 1 .

Table 1. Variable description and sources: potential determinants of public debt

\begin{tabular}{|c|c|c|c|}
\hline $\mathbf{N}$ & Variable & Description & Source \\
\hline 1 & debt & Public debt (\% of GDP) & IMF data \\
\hline 2 & bud_bal & Budget balance (\% of GDP) & IMF data \\
\hline 3 & infl & Inflation $(\%)$ & IMF data \\
\hline 4 & exch_cpi & Real effective exchange rate (CPI-based) & IMF data \\
\hline 5 & int $r$ & Real interest rate $(\%)$ & IMF data \\
\hline 6 & hipc & Highly indebted poor countries initiative & IMF classification \\
\hline 7 & gdpg & GDP growth (\%) & World Bank data \\
\hline 8 & gfinv & Gross fixed investment ( $\%$ of GDP) & World Bank data \\
\hline 9 & nat_ress & Natural resources rents (\% of GDP) & World Bank data \\
\hline 10 & $\mathrm{~m} 2$ & M2 (\% of GDP) & World Bank data \\
\hline 11 & pop_r & Population growth $(\%)$ & World Bank data \\
\hline 12 & open & Trade openness (computed) & World Bank data \\
\hline 13 & debt_ser & Debt-service paid/GDP & World Bank data \\
\hline 14 & imp_cov & Import cover (months) & World Bank data \\
\hline 15 & cred_fin & Domestic credit provided by financial sector ( $\%$ of GDP) & World Bank data \\
\hline 16 & aid & Official development assistance ( $\%$ of GDP) & World Bank data \\
\hline 17 & rgdpc & Real GDP per head (\$ at PPP) & World Bank data \\
\hline 18 & hk_2 & School enrollment, secondary $(\%)$ & World Bank data \\
\hline 19 & mobil_1000 & Mobile cellular subscriptions (per 1000 people) & World Bank data \\
\hline 20 & $\operatorname{miexp}$ & Military expenditure (\% of GDP) & SIPRI data \\
\hline 21 & arm_imp & Arms imports (SIPRI trend indicator values) & SIPRI data \\
\hline 22 & presid & Presidential elections & NELDA database \\
\hline 23 & legis & Legislative elections & NELDA database \\
\hline 24 & assem & Constituent Assembly elections & NELDA database \\
\hline 25 & pol_sys & Political regime type & NELDA database \\
\hline 26 & soc_index & Socioeconomic Conditions index & ICRG data \\
\hline 27 & gov_index & Government Stability index & ICRG data \\
\hline 28 & corr_index & Corruption index & ICRG data \\
\hline
\end{tabular}

Note: Data sources are IMF, World Bank, SIPRI, NELDA and ICRG databases. The sample period covers the years from 1990 to 2018. 
The second dataset is the World Development Indicators (WDI) of the World Bank. Basing on the literature review (Fatás et al., 2019; Sadik-Zada and Gatto, 2019; Forslund et al., 2011) we extracted some socio economic variables including GDP growth, real GDP per head, gross fixed investment, official development assistance, debt-service paid, money supply (M2), domestic credit provided by financial sector, trade (imports and exports), natural resources rents, mobile cellular subscriptions (per 1000 people), population growth and school enrollment. Regarding data on military expenditure and arms imports, it's provided by the Stockholm International Peace Research Institute (SIPRI) database.

A last group of variables reflecting institutional and political conditions is made up of socioeconomic conditions, corruption and government stability [from the International Country Risk Guide (ICRG) data] and elections events [from National Elections Across Democracy and Autocracy (NELDA) dataset] provided by Hyde and Marinov (2019). According to Bayale et al. (2020), Fatás et al. (2019), Bohn and Veiga (2019), Alesina and Passalacqua (2016) and Forslund et al. (2011), instructional factors as well as electoral cycles (pollical factors) may also generate different incentives to borrow.

\section{Bayesian Model Averaging (BMA)}

The BMA addresses model uncertainty in a canonical regression problem. As specified in equation (1), suppose a linear model structure, with $y$ being the dependent variable (public debt), $\alpha_{\gamma}$ a constant, $\beta_{\gamma}$ the coefficients, and $\varepsilon$ a normal (iid) error term with variance $\sigma^{2}$ :

$$
y=\alpha_{\gamma}+X_{\gamma} \beta_{\gamma}+\varepsilon, \quad \varepsilon \sim N\left(0 ; \sigma^{2} I\right)
$$

A problem arises when there are many potential explanatory variables in a matrix $X$ : which variables $X_{\gamma} \in\{X\}$ should be then included in the model? And how important are they? In fact, the direct approach to do inference on a single linear model that includes all variables is inefficient or even infeasible with a limited number of observations (Moral-Benito, 2015; Forte et al., 2018; Bayale, 2020). The BMA tackles the problem by estimating models for all possible combinations of $\{X\}$ and constructing a weighted average over all of them. If $X$ contains $K$ potential variables, this means estimating $2^{K}$ variable combinations and thus $2^{K}$ models (Zeugner and Feldkircher, 2015; Raftery et al., 2017). The model weights for this averaging stem from posterior model probabilities that arise from Bayes' theorem:

$$
p\left(M_{\gamma} \mid y, X\right)=\frac{p\left(y \mid M_{\gamma}, X\right) p\left(M_{\gamma}\right)}{p(y \mid X)}=\frac{p\left(y \mid M_{\gamma}, X\right) p\left(M_{\gamma}\right)}{\sum_{s=1}^{2^{K}} p\left(y \mid M_{s}, X\right) p\left(M_{s}\right)}
$$

where, $p(y / X)$ denotes the integrated likelihood which is constant over all models and is thus simply a multiplicative term (Zeugner and Feldkircher, 2015; Okafor and Piesse, 2017). Therefore, the posterior model probability (PMP) is proportional to the integrated likelihood $p\left(y / M_{\gamma}, X\right)$, which reflects the probability of the data given model $M_{\gamma}$. The marginal likelihood of model $M_{\gamma}$ is multiplied by its prior model probability $p\left(M_{\gamma}\right)$ indicating how probable the researcher thinks model $M_{\gamma}$ is before looking at the data (Moral-Benito, 2015; Forte et al., 2018). The difference between $p(y / X)$ and $p\left(y / M_{\gamma}, X\right)$ is that integration is once over the model space $(p(y / X))$ and once for a given model over the parameter space 
$p\left(y / M_{\gamma}, X\right)$. By re-normalization of the product from above one can infer the PMPs and thus the model weighted posterior distribution for any statistic $\theta$ :

$$
p(\theta \mid y, X)=\sum_{\gamma=1}^{2^{K}} p\left(\theta \mid M_{\gamma}, y, X\right) \frac{p\left(M_{\gamma} \mid X, y\right) p\left(M_{\gamma}\right)}{\sum_{s=1}^{2^{K}} p\left(M_{S} \mid p\left(M_{S}\right)\right)}
$$

The model prior $p\left(M_{\gamma}\right)$ has to be elicited by the researcher and should reflect prior beliefs. A popular choice is to set a uniform prior probability for each model $p\left(M_{\gamma}\right) \propto 1$ to represent the lack of prior knowledge. The specific expressions for the marginal likelihoods $p\left(M_{\gamma} \mid y, X\right)$ and the posterior distributions $p\left(\theta \mid M_{\gamma}, y, X\right)$ depend on the chosen estimation framework. The literature standard is to use a Bayesian regression linear model with a specific prior structure called Zellner's $g$ prior. For each individual model $M_{\gamma}$ suppose a normal error structure as in (1). The need to obtain posterior distributions requires to specify the priors on the model parameters (Zeugner and Feldkircher, 2015; Okafor and Piesse, 2017; SansoNavarro and Vera-Cabello, 2018, Bayale, 2020). Here, we place "improper" priors on the constant and error variance, which means they are evenly distributed over their domain: $p\left(\alpha_{\gamma}\right) \propto 1$, in other words, complete prior uncertainty where the constant is located. Similarly, set $p(\sigma) \propto \sigma^{-1}$. The crucial prior is the one on the regression coefficients $\beta_{\gamma}$. Before looking at the data $(y, X)$, we formulate our prior beliefs on coefficients into a normal distribution with a specified mean and variance (Zeugner and Feldkircher, 2015). It is common to assume a conservative prior mean of zero for the coefficients to reflect that not much is known about them. Their variance structure is defined according to Zellner's g: $g \sigma^{2}\left(X_{\gamma}^{T} X_{\gamma}\right)^{-1}$ is:

$$
\left(\beta_{\gamma} \mid g\right) \sim N\left(0, g \sigma^{2}\left(X_{\gamma}{ }^{T} X_{\gamma}\right)^{-1}\right)
$$

This means that we assume that coefficients are zero, and that their variance-covariance structure is broadly in line with that of the data $X_{\gamma}$. The hyperparameter $g$ embodies how certain we are that coefficients are indeed zero: A small $g$ means small prior coefficient variance and therefore implies we are quite certain that the coefficients are indeed zero. In contrast, a large $g$ means that the researcher is very uncertain that coefficients are zero (Zeugner and Feldkircher, 2015; Raftery et al., 2017; Bayale, 2020). The posterior distribution of coefficients reflects prior uncertainty: Given $g$, it follows a t-distribution with expected value $E\left(\beta_{\gamma} \mid y, X, g, M_{\gamma}\right)=\frac{g}{1+g} \hat{\beta}_{\gamma}$, where $\hat{\beta}_{\gamma}$ is the standard OLS estimator for model $\gamma$ (Moral-Benito, 2015; Forte et al., 2018). The expected value of coefficients is thus a convex combination of OLS estimator and prior mean. The more conservative $g$, the more important is the prior, and the more the expected value of coefficients is shrunk toward the prior mean zero. As $g \rightarrow \infty$, the coefficient estimator approaches the OLS estimator. Similarly, the posterior variance of $\beta_{\gamma}$ is affected by the choice of $g$ :

$$
\operatorname{COV}\left(\beta_{\gamma} \mid y, X, g, M_{\gamma}\right)=\frac{(y-\bar{y})^{T}(y-\bar{y})}{N-3} \frac{g}{1+g}\left(1-\frac{g}{1+g} R_{\gamma}^{2}\right)\left(X_{\gamma}{ }^{T} X_{\gamma}\right)^{-1}
$$

In others words, the posterior covariance is similar to that of the OLS estimator times a factor that includes g (Zeugner and Feldkircher, 2015; Sanso-Navarro and Vera-Cabello, 2018). For 
BMA, this prior framework results in a very simple marginal likelihood $p\left(y \mid M_{\gamma}, X, g\right)$, that is related to the R-squared and includes a size penalty factor adjusting for model size $k_{\gamma}$ :

$$
p\left(y \mid M_{y}, X, g\right)=(y-\bar{y})^{T}(y-\bar{y})^{-\frac{N-1}{2}}(1+g)^{-\frac{k_{\gamma}}{2}}\left(1-\frac{g}{1+g}\right)^{-\frac{N-1}{2}}
$$

So, the crucial choice here concerns the form of the hyperparameter g. A popular "default" approach is the "unit information prior" (UIP), which sets $g=N$ commonly for all models and thus attributes about the same information to the prior as is contained in one observation (Zeugner and Feldkircher, 2015; Raftery et al., 2017).

\section{Determinants of Public Debt in Africa}

\subsection{Main Results}

In line with the aim of this paper, Table 2 shows the results obtained from applying the BMA approach in a panel data regression framework. The upper part of the table shows the variable names and their corresponding statistics while the lower part of the table presents model size and model priors such as the number of observations $(1,479)$, the number of models visited $(34,303)$ and the posterior expected model size (average number of included regressors), which is equal to 12.18 in our case. In the Table, the first three columns report, for each variable, the PIP (in value terms) and the mean and standard deviation of estimated coefficients when African public debt is considered. These latter figures can be interpreted, respectively, as a BMA point estimation and standard error (Sanso-Navarro and Vera-Cabello, 2018; Bayale, 2020).

It can be observed that official development assistance, trade openness, debt-service paid, military expenditure, real interest rate, government stability index, political regime type and the domestic credit provided by financial sector are priority variables that are included in the models visited. A part from this first group of variables, high PIPs are also observed for budget balance, mobile cellular subscriptions (infrastructure indicator) and real effective exchange rate. When we look at the posterior mean of each coefficient of the identified variables from model averaging, we can comment that real interest rate, political regime type, budget balance, mobile cellular subscriptions, real effective exchange rate are regressors with high PIPs and a negative influence on public debt in Africa. Corruption index, highly indebted poor countries initiative, GDP growth, socioeconomic conditions index, gross fixed investment, money supply, population growth and legislative elections have a negative influence on public debt, but with very lower PIPs. In contrary, official development assistance, trade openness, debt-service paid, military expenditure, credit provided by financial sector, arms imports, inflation, natural resources rents and presidential elections are increasing public debt in Africa.

A visual summary of the results described above is shown in Figure 1.1 which presents the cumulative baseline model probabilities. Each graph ranks, vertically, the potential determinants of public debt according to their PIPs. Moreover, selected models are ordered, horizontally, taking into account their posterior probability, which is proportional to the column width. A colored rectangle reflects that the variable is included in the model and 
indicates the sign of its estimated influence (blue when positive and red when negative). For each specification, official development assistance, military expenditure and real interest rate are consistently included in all selected models. Other variables that display high PIPs are trade openness, debt-service paid, government stability index, political regime type, domestic credit provided by financial sector and budget balance.

Table 2: Bayesian model averaging results (Baseline)

\begin{tabular}{|c|c|c|c|c|c|}
\hline & PIP & Post Mean & Post SD & Cond.Pos.Sign & Idx \\
\hline aid & 1.0000 & 0.2061 & 0.0283 & 1.0000 & 1 \\
\hline open & 1.0000 & 0.1297 & 0.0254 & 1.0000 & 2 \\
\hline debt_ser & 1.0000 & 0.1422 & 0.0262 & 1.0000 & 3 \\
\hline $\operatorname{miexp}$ & 1.0000 & 0.1922 & 0.0300 & 1.0000 & 17 \\
\hline int_r $r$ & 1.0000 & -0.2128 & 0.0303 & 0.0000 & 18 \\
\hline gov_index & 1.0000 & 0.1586 & 0.0257 & 1.0000 & 19 \\
\hline pol_sys & 1.0000 & -0.1621 & 0.0295 & 0.0000 & 22 \\
\hline cred_fin & 1.0000 & 0.3023 & 0.0263 & 1.0000 & 27 \\
\hline bud bal & 0.9834 & -0.0896 & 0.0268 & 0.0000 & 10 \\
\hline mobil 1000 & 0.6976 & -0.0556 & 0.0432 & 0.0000 & 26 \\
\hline exch_cpi & 0.5998 & -0.0422 & 0.0395 & 0.0000 & 9 \\
\hline corr_index & 0.4143 & -0.0296 & 0.0393 & 0.0000 & 21 \\
\hline arm_imp & 0.3909 & 0.0247 & 0.0348 & 1.0000 & 11 \\
\hline hipc & 0.2188 & -0.0136 & 0.0287 & 0.0000 & 23 \\
\hline imp_cov & 0.1760 & 0.0092 & 0.0225 & 1.0000 & 16 \\
\hline infl & 0.0813 & 0.0035 & 0.0136 & 1.0000 & 13 \\
\hline rgdpc & 0.0641 & 0.0034 & 0.0147 & 1.0000 & 15 \\
\hline gdpg & 0.0569 & -0.0021 & 0.0103 & 0.0000 & 7 \\
\hline soc_index & 0.0446 & -0.0017 & 0.0100 & 0.0157 & 20 \\
\hline gfinv & 0.0408 & -0.0013 & 0.0084 & 0.0000 & 8 \\
\hline nat_ress & 0.0256 & 0.0007 & 0.0060 & 1.0000 & 24 \\
\hline assem & 0.0249 & 0.0006 & 0.0053 & 1.0000 & 6 \\
\hline hk_2 & 0.0175 & 0.0003 & 0.0043 & 1.0000 & 25 \\
\hline i_ctry & 0.0168 & 0.0002 & 0.0041 & 0.9806 & 28 \\
\hline$\overline{\mathrm{m}} 2$ & 0.0162 & -0.0002 & 0.0036 & 0.0000 & 12 \\
\hline presid & 0.0151 & 0.0002 & 0.0033 & 1.0000 & 4 \\
\hline pop_r & 0.0137 & -0.0001 & 0.0032 & 0.0857 & 14 \\
\hline legis & 0.0123 & -0.0000 & 0.0026 & 0.0000 & 5 \\
\hline \multicolumn{2}{|c|}{ Mean no. regressors } & 12.1822 & Model spac & & $2.7 \mathrm{e}+08$ \\
\hline \multicolumn{2}{|c|}{ No. models visited } & 34,303 & No. Obs. & & 1,479 \\
\hline
\end{tabular}

Note: PIP denotes the posterior inclusion probability of each variable. Mean and SD are the posterior mean and standard deviation of each coefficient from model averaging, respectively. Cond.Pos.Sign, the conditional posterior probability inclusion, sign certainty and Idx denotes the index of the variables. 
Figure 1.1 : Cumulative model probabilities (baseline)

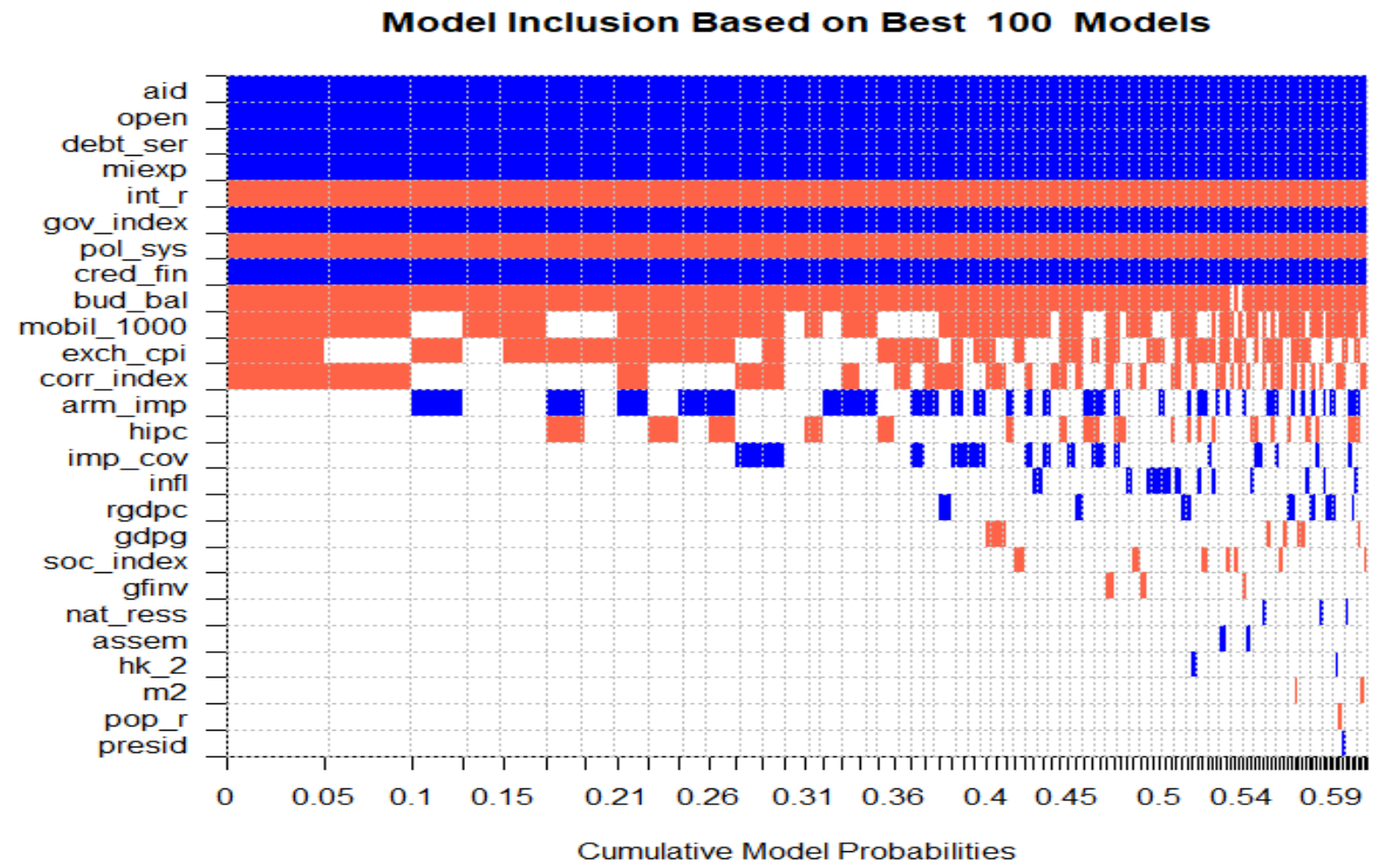

Figure 1.2 : Size and index of models (baseline)

Figure 1.3 : Response variable (baseline)
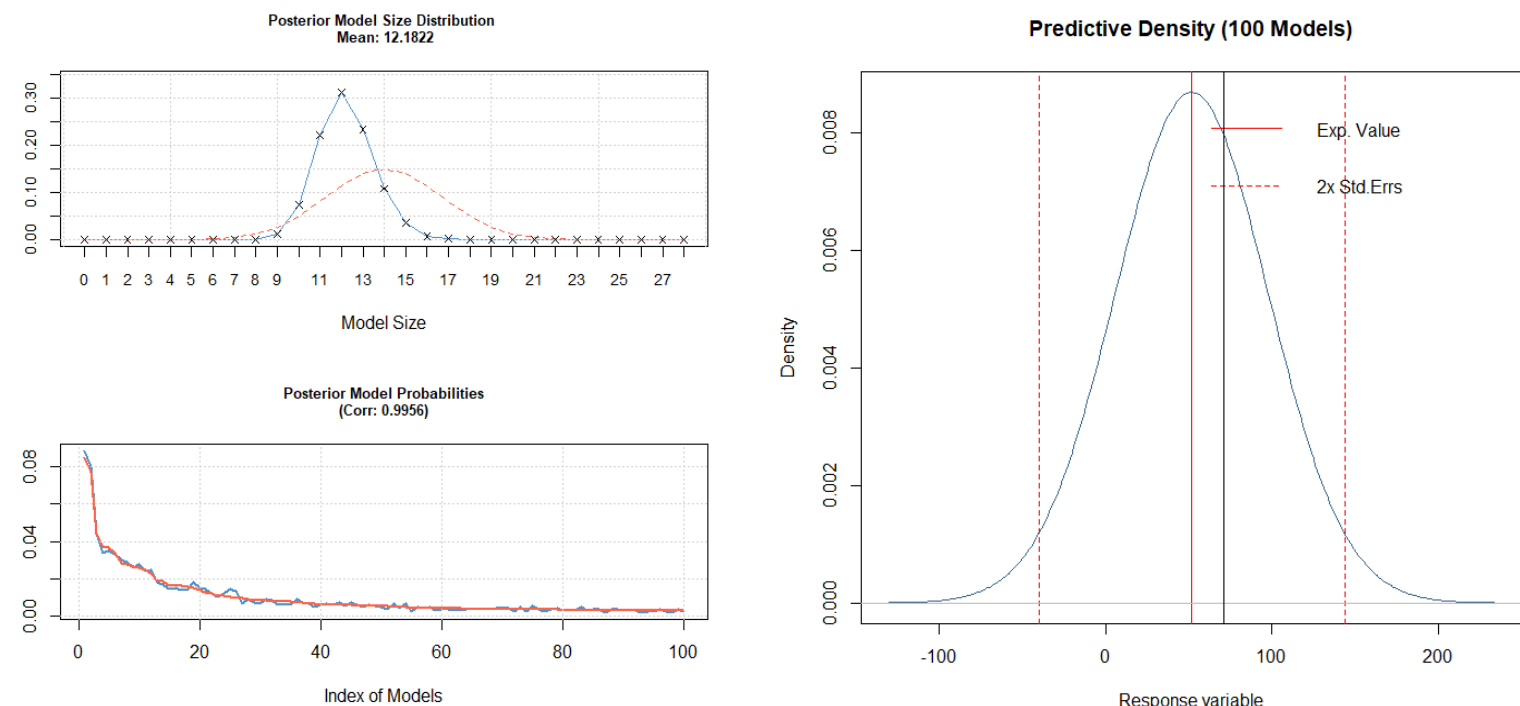

Note. Fig. 2.1 is the image plot: Blue color corresponds to a positive coefficient, red to a negative coefficient, and white to non-inclusion of the respective variable. The horizontal axis is scaled by the models' posterior model probabilities. Fig. 2.2 contains distribution of posterior model size (custom prior on the model space employed) and convergence plot of 100 models, respectively. Fig. 2.3 is a posterior predictive density for public debt in Africa: Solid red line denotes the expected value of the forecast, dashed red lines a $+/-2$ standard deviations interval. 
Beyond these results, Figure 1.2 indicates that the model achieved a decent level of correlation among analytical likelihoods and iteration counts with a comparatively small number of sampling draws. Finally, Figure 1.3 shows that, the density of debt for Africa is high (similar to the mode of the predictive density). There are not significant outliers in debt data. So, the whole distribution of the forecast is consistent.

\subsection{Robustness Checks}

To ensure the robustness of our results on the determinants of public debt in Africa, we look deeply at the economic literature to find potentially irregular factors that could affect the accumulation of debt in Africa. In this regard, according to the seminar papers of Jordà et al., (2011), De Fiore and Uhlig (2015) and Wee et al. (2020), the international economic context such as financial or sanitary crises are likely to be factors favouring the accumulation of debt in countries. So, we add to our model one variable that can capture crises effect on debt. That variable was constructed as a dummy, with a value of 1 in crises years and 0 otherwise. We also consider regional dummies representing the five regions according to the United Nations Economic Commission for Africa (UNECA): North Africa, West Africa, Central Africa, East Africa and Southern Africa. This allow us to proxy for the possible presence of unobserved heterogeneity by region in our database.

Table 3 and Figures 2.1, 2.2 and 2.3 exhibit the robustness analysis results. The introduction of socio-economic crises and regional dummies does not alter the main conclusions drawn about the regressors with a more robust relationship with public debt. Almost all the variables that have been introduced have PIPs lower than 0.5 point. Looking at their posterior coefficients, we can note that crises have a positive influence on public debt in Africa. This means that socio-economic crises are likely to increase debt (De Fiore and Uhlig, 2015, Wee et al., 2020). At the regional level, it can be observed that belonging to Central Africa seems to increase the probability of indebtedness since its coefficient is positive. This is not the case for the four other regions of Africa. Overall, the high inclusion probabilities of variables that were observed in the baseline results do not change. 
Table 3: Bayesian model averaging results (Robustness check)

\begin{tabular}{|c|c|c|c|c|c|}
\hline & PIP & Post Mean & Post SD & Cond.Pos.Sign & $\mathrm{Idx}$ \\
\hline aid & 1.0000 & 0.2058 & 0.0283 & 1.0000 & 1 \\
\hline open & 1.0000 & 0.1281 & 0.0256 & 1.0000 & 2 \\
\hline debt_ser & 1.0000 & 0.1424 & 0.0262 & 1.0000 & 3 \\
\hline $\operatorname{miexp}$ & 1.0000 & 0.1933 & 0.0301 & 1.0000 & 23 \\
\hline int_r & 1.0000 & -0.2123 & 0.0302 & 0.0000 & 24 \\
\hline gov_index & 1.0000 & 0.1582 & 0.0257 & 1.0000 & 25 \\
\hline pol_sys & 1.0000 & -0.1618 & 0.0294 & 0.0000 & 28 \\
\hline cred_fin & 1.0000 & 0.3028 & 0.0262 & 1.0000 & 33 \\
\hline bud_bal & 0.9881 & -0.0902 & 0.0262 & 0.0000 & 16 \\
\hline mobil_1000 & 0.6597 & -0.0521 & 0.0436 & 0.0000 & 32 \\
\hline exch_cpi & 0.6314 & -0.0451 & 0.0397 & 0.0000 & 15 \\
\hline corr_index & 0.4121 & -0.0299 & 0.0397 & 0.0000 & 27 \\
\hline arm_imp & 0.3944 & 0.0254 & 0.0352 & 1.0000 & 17 \\
\hline hipc & 0.2499 & -0.0167 & 0.0322 & 0.0000 & 29 \\
\hline imp_cov & 0.1541 & 0.0081 & 0.0212 & 1.0000 & 22 \\
\hline crisis & 0.1263 & 0.0069 & 0.0206 & 0.0000 & 4 \\
\hline infl & 0.0679 & 0.0029 & 0.0126 & 1.0000 & 19 \\
\hline rgdpc & 0.0484 & 0.0024 & 0.0127 & 1.0000 & 21 \\
\hline gdpg & 0.0445 & -0.0016 & 0.0091 & 0.0000 & 13 \\
\hline soc_index & 0.0392 & -0.0016 & 0.0100 & 0.0151 & 26 \\
\hline gfinv & 0.0315 & -0.0011 & 0.0074 & 0.0000 & 14 \\
\hline sout_africa & 0.0281 & -0.0009 & 0.0067 & 0.0000 & 8 \\
\hline cent_africa & 0.0177 & 0.0004 & 0.0044 & 1.0000 & 5 \\
\hline assem & 0.0175 & 0.0004 & 0.0045 & 1.0000 & 12 \\
\hline nat_ress & 0.0175 & 0.0004 & 0.0049 & 1.0000 & 30 \\
\hline wst_africa & 0.0166 & -0.0004 & 0.0043 & 0.0000 & 9 \\
\hline hk_ 2 & 0.0123 & 0.0002 & 0.0036 & 1.0000 & 31 \\
\hline $\mathrm{m} 2$ & 0.0113 & -0.0001 & 0.0030 & 0.0000 & 18 \\
\hline i_ctry & 0.0110 & 0.0001 & 0.0033 & 0.9620 & 34 \\
\hline aest_africa & 0.0105 & -0.0001 & 0.0029 & 0.0000 & 6 \\
\hline presid & 0.0101 & 0.0001 & 0.0027 & 1.0000 & 10 \\
\hline nor_africa & 0.0101 & -0.0001 & 0.0028 & 0.0000 & 7 \\
\hline pop_r & 0.0099 & -0.0001 & 0.0028 & 0.0762 & 20 \\
\hline legis & 0.0082 & -0.0003 & 0.0021 & 0.0000 & 11 \\
\hline Mean no. regressors & & 12.5855 & Model space $2^{l}$ & & $1.7 \mathrm{e}+10$ \\
\hline No. models visited & & 32,654 & No. Obs. & & 1,479 \\
\hline
\end{tabular}

Note: PIP denotes the posterior inclusion probability of each variable. Mean and SD are the posterior mean and standard deviation of each coefficient from model averaging, respectively. Cond.Pos.Sign, the conditional posterior probability inclusion, sign certainty and Idx denotes the index of the variables. 
Figure 2.1 : Cumulative model probabilities (robustness check)

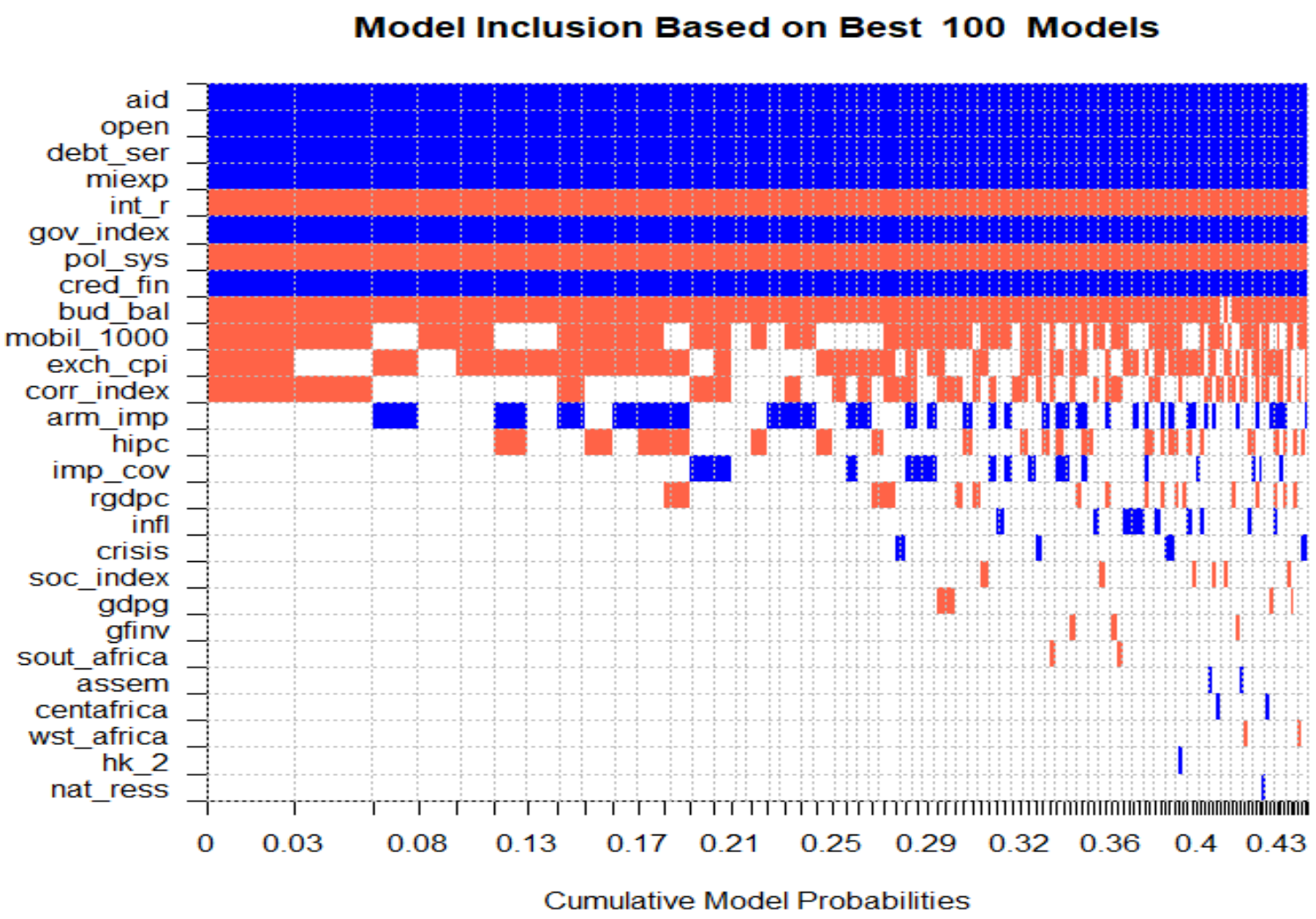

Figure 2.2: Size and index of models (robustness check)

Figure 2.3: Response variable (robustness check)
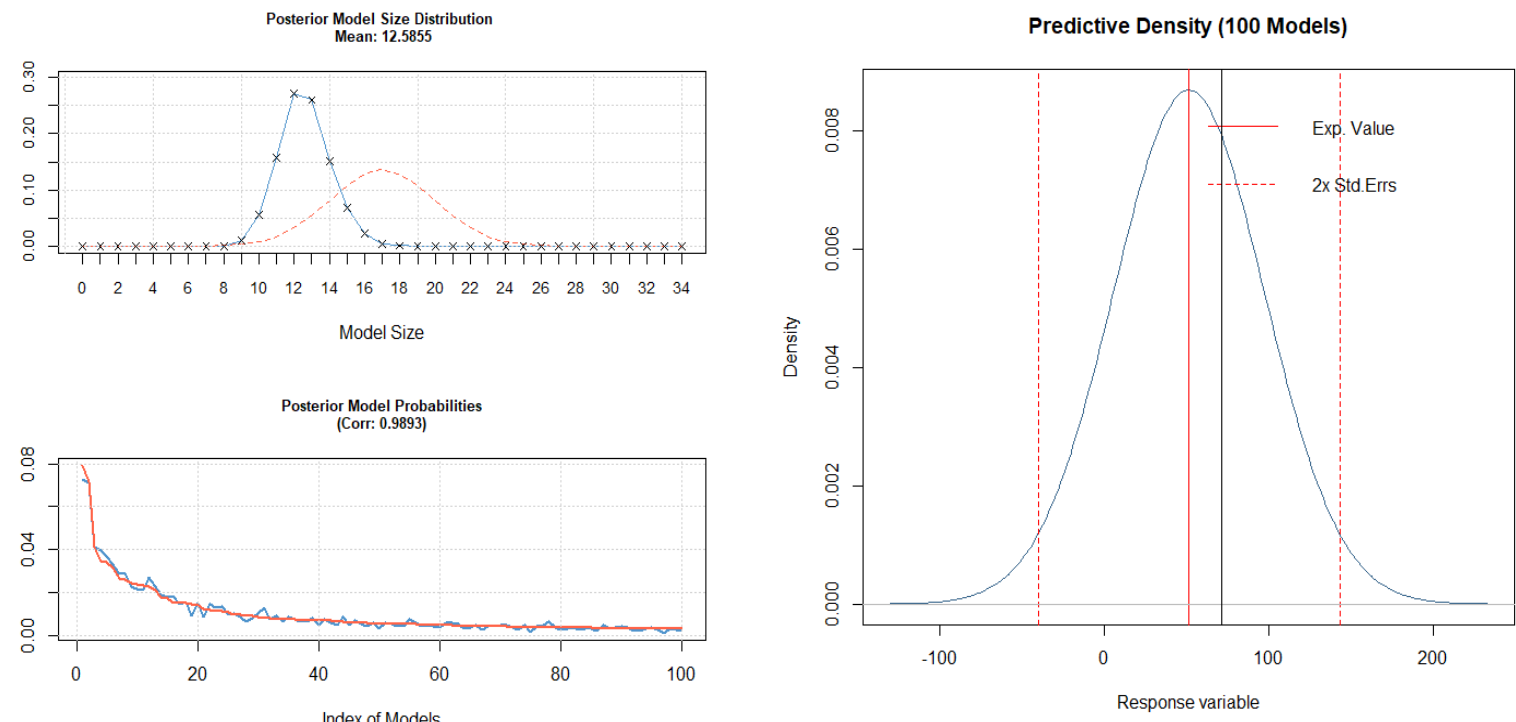

Note. Fig. 2.1 is the image plot: Blue color corresponds to a positive coefficient, red to a negative coefficient, and white to non-inclusion of the respective variable. The horizontal axis is scaled by the models' posterior model probabilities. Fig. 2.2 contains distribution of posterior model size (custom prior on the model space employed) and convergence plot of 100 models, respectively. Fig. 2.3 is a posterior predictive density for public debt in Africa: Solid red line denotes the expected value of the forecast, dashed red lines a +/- 2 standard deviations interval. 


\section{Concluding remarks}

This paper contributes to the empirical literature on the determinants of public debt in Africa by introducing model uncertainty to cover the period spanning from 1990 to 2018. With this aim, a Bayesian Model Averaging (BMA), which is a sound methodological approach, has been implemented within a panel data regression framework (Zeugner and Feldkircher, 2015; Raftery et al., 2017; Clyde, 2018; Sanso-Navarro and Vera-Cabello, 2018). In this way, we have been able to take into account the possible presence of unobserved heterogeneity by country in our database. Also, regional dummies were taken into account. For, each variable of the model, the PIP, the mean and standard deviation coefficients are estimated. Likewise, cumulative model probabilities, size and index of models and posterior predictive density for public debt in Africa (response variable) were presented and analyzed to check the consistency of the whole model (Zeugner and Feldkircher, 2015).

The empirical findings support the fact that official development assistance, trade openness, military expenditure, real interest rate, debt-service paid, the domestic credit provided by financial sector, government stability index, political regime type, real effective exchange rate, budget balance and mobile cellular subscriptions, which captures infrastructure indicator are the main determinants of public debt accumulation in Africa. For this group of variables high PIPs are observed. In contrast, some socioeconomic and political factors such as GDP growth, gross fixed investment, natural resources, money supply, population growth, inflation, human capital, corruption index, socioeconomic conditions index and elections (presidential, legislative and constituent assembly) events have registered lower PIPs, showing that these factors have very little influence on public debt (Bayale and Tchagnao, 2020). It should be also noted that, the taking into account of the economic crises and heterogeneity by region does not change the main conclusions. This paper contributed to the literature on the determinants of debt and have shed light on the role of economic, institutional and political factors in the accumulation of debt in Africa (Fatás et al, 2019; Forslund at al., 2011). It explores the various and multiple factors that can explain public debt in Africa (Wee et al., 2020).

In this regard, our results imply that very profound economic, policy and institutional reforms are critically required in managing and controlling the level of indebtedness for debt sustainability in Africa. For instance, efficiency in the classic tax collection, transparency and the use of local currency bond markets are possibilities that should not be overlooked. Likewise, sound fiscal policy coupled with real monetary policy would be important. In fact, this is why future research could examine in greater depth how specific institutional frameworks, such as fiscal rules, inflation targeting or robust financial supervision and regulation public debt and its composition in some specific African economic and / or monetary zones, in order to allow comparisons to be made at the regional level. 


\section{Declarations}

Availability of data and material

The datasets generated and materials used during and/or analyzed during the current study are available from the corresponding author on reasonable request.

\section{Competing interests}

The Author wishes to confirm that there are no known conflicts of interest associated with this publication.

\section{Funding}

The author received no specific funding for this work.

\section{Authors' contributions}

I am the only author of the manuscript. I worked, read and approved the final manuscript.

\section{Acknowledgements}

The author would like to thank the United Nations Economic Commission for Africa (UNECA) for the use of their facilities during the completion of this paper as a Research Fellow with the Macroeconomics and Governance Division (MGD). The views expressed are those of the author and do not represent that of the United Nations (UN).

\section{Authors' information}

Nimonka Bayale (Ph.D) is currently a Research Fellow with the Macroeconomic and Governance Division (MGD), United Nations Economic Commission for Africa (UNECA), Addis Ababa, Ethiopia. He was previously a Research Assistant with the West African Economic and Monetary Union (WAEMU) Commission in Ouagadougou (Burkina Faso) and with the International Food Policy Research Institute (IFPRI) in Dakar (Senegal) under the WAEMU Commission Research Fellowship Program. He is a Researcher and Lecturer of Economics at the University of Kara, Togo. His research interests are in the fields of Development Economics, International Economics, Regional Integration and Economic Policy modelling. 


\section{References}

African Development Bank. (2018). African Economic Outlook 2018. https://www.afdb.org/fileadmin/uploads/afdb/Documents/Publications/African Economic Ou tlook_2018_-_EN.pdf

Alesina, A. \& Passalacqua, A. (2016). The Political Economy of Government Debt. Chap. 33 of the Handbook of Macroeconomics Vol. 2, 2599-2651.

Atta-Mensah, J., \& Ibrahim, M. (2020). Explaining Africa's Debt: The Journey So Far and the Arith-metic of the Policymaker. Theoretical Economics Letters, 10, 409-441. https://doi.org/10.4236/tel.2020.102027.

Aybarç, S. (2019). Theory of Public Debt and Current Reflections. In Public Economics and Finance. IntechOpen. DOI: http://dx.doi.org/10.5772/intechopen.82730.

Bayale, N. (2020, Forthcoming). Empirical Investigation into the Determinants of Foreign Aid in Sahel Countries: A Panel Bayesian Model Averaging Approach. Defence and Peace Economics.

Bayale, N., Tchagnao, A-F., \& Chavula, K. H. (2020, Forthcoming). Elections and Public debt: Evidence from Africa. African Review of Economics and Finance, Vol. 12, N.2.

Bilan, I. (2016). Overview of the Main Theories on the Economic Effects of Public Indebtedness. In European Integration-Realities and Perspectives Proceedings (pp. 356-362). Editura Universitară Danubius.

Bohn, F. \& Veiga, F. J. (2019). Elections, recession expectations and excessive debt: an unholy trinity. Public Choice. (180), 429-449. https://doi.org/10.1007/s11127-019-00647-x.

Calderón, C. \& Zeufack, A. G. (2020). Borrow with Sorrow? The Changing Risk Profile of Sub-Saharan Africa's Debt. World Bank PRWP. № 9137.

Chiminya, A., \& Nicolaidou, E. (2015). An empirical investigation into the determinants of external debt in Sub Saharan Africa. In Biennial Conference of The Economic Society of South Africa, University of Cape Town.

Clyde, M. (2018). BAS: Bayesian Adaptive Sampling for Bayesian Model Averaging. R Package Version 1.5.0. doi:10.5281/zenodo.59497.

De Fiore, F., \& Uhlig, H. (2015). Corporate debt structure and the financial crisis. Journal of Money, credit and Banking, 47(8), 1571-1598.

Easterly, W. (2002). How did heavily indebted poor countries become heavily indebted? Reviewing two decades of debt relief. World Development, 30(10), 1677-1696.

Economic Commission for Africa (ECA, 2019). Fiscal Policy for Financing Sustainable Development in Africa. Economic Report on Africa 2019. United Nations, Addis Ababa, Ethiopia.

Fatás, A., Ghosh, A. R., Panizza, U. \& Presbitero, A. F. (2019). The Motives to Borrow. International Monetary Fund (IMF) Working Papers, WP/19/101. 
Forslund, K., Limab, L. \& Panizza, U. (2011). The determinants of the composition of public debt in developing and emerging market countries. Review of Development Finance, (1), 207222 .

Forte, A., G. Garcia-Donato, \& M. Steel. (2018). Methods and Tools for Bayesian Variable Selection and Model Averaging in Normal Linear Regression. International Statistical Review 86 (2): 237-258. doi:10.1111/insr.12249.

Hyde, S. D. \& Marinov, N. (2019). Codebook for National Elections Across Democracy and Autocracy (NELDA) Dataset, Version 5.0. Version Released November 20, 2019; Last Updated November 13, 2019.

International Monetary Fund (IMF, 2019). Recovery amid elevated uncertainty. Regional Economic Outlook: Sub-Saharan Africa. Washington, DC, April.

Iyoha, M. (2000). An Econometric Analysis of External Debt and Economic Growth in SubSaharan African Countries in External Debt and Capital Flights in Sub-Saharan Africa. Eds SI Ajayi and M. Khan. Washington, DC: IMF.

Jordà, Ò., M. Schularick, and A. M. Taylor. (2011). Financial Crises, Credit Booms, and External Imbalances: 140 Years of Lessons. IMF Economic Review 59 (2): 340-378.

Karazijienè, Ž. (2015). Critical analysis of public debt and tendencies of its management. Public Policy and Administration, 14(2), 194-208.

Ksantini, M. (2016). The Determinants of Public Debt. Romanian Economic Journal, 18(59), 111-124.

Moral-Benito, E. (2015). Model Averaging in Economics: An Overview. Journal of Economic Surveys 29 (1): 46-75. doi:10.1111/joes.12044.

Okafor, G., and J. Piesse. (2017). Empirical Investigation into the Determinants of Terrorism: Evidence from Fragile States. Defence and Peace Economics (12),1-15.

Raftery, A., J. Hoeting, C. Volinsky, I. Painter, and K. Y. Yeung. 2017. "BMA: Bayesian Model Averaging." R Package Version 3.18.7: 1-46.

Sadik-Zada, E. R. \& Gatto, A. (2019). Determinants of the Public Debt and the Role of the Natural Resources: A Cross-Country Analysis. Working paper 004, Economic Theory.

Sanso-Navarro, M \& Vera-Cabello, M. (2018). The Socioeconomic Determinants of Terrorism: A Bayesian Model Averaging Approach, Defence and Peace Economics, DOI: https://doi.org/10.1080/10242694.2018.1525935

Wee Chian Koh, M. Ayhan Kose, Peter S. Nagle, Franziska L. Ohnsorge, and Naotaka Sugawara. (2020). Debt and Financial Crises. World Bank PRWP. 9116.

World Bank Group. (2019). International Debt Statistics 2019. World Bank, Washington, DC. https://openknowledge.worldbank.org/handle/10986/30851

Zdravković, A. (2019). Determinants of Public Debt and Fiscal Sustainability (Doctoral dissertation, University Union, Belgrade Banking Academy). 
Zeugner, S., \& M. Feldkircher. (2015). Bayesian Model Averaging Employing Fixed and Flexible Priors: The BMS Package for R. Journal of Statistical Software, 68 (4), 1-37.

\section{Appendix}

\section{Appendix I. List of countries in the sample}

The countries that have been included in the empirical analysis carried out in the present study are Algeria, Angola, Benin, Botswana, Burkina Faso, Burundi, Cameroon, Cabo Verde, Central African Republic, Chad, Comoros, Dem. Rep. of Congo, Congo, Côte d'Ivoire, Djibouti, Egypt, Equatorial Guinea, Eswatini, Ethiopia, Gabon, Gambia, Ghana, Guinea, Guinea-Bissau, Kenya, Lesotho, Liberia, Libya, Madagascar, Malawi, Mali, Mauritania, Mauritius, Morocco, Mozambique, Namibia, Niger, Nigeria, Rwanda, São Tomé and Principe, Senegal, Seychelles, Sierra Leone, South Africa, Sudan, Tanzania, Togo, Tunisia, Uganda, Zambia and Zimbabwe.

The study period is spanning from 1990 to 2018.

For robustness analysis, these countries have been grouped according to their geographic region following the United Nations Economic Commission for Africa (UNECA)'s list of economies (Central Africa, Eastern Africa, North Africa, Southern Africa and West Africa). 


\section{Figures}

Figure 1.1 : Cumulative model probabilities (baseline)

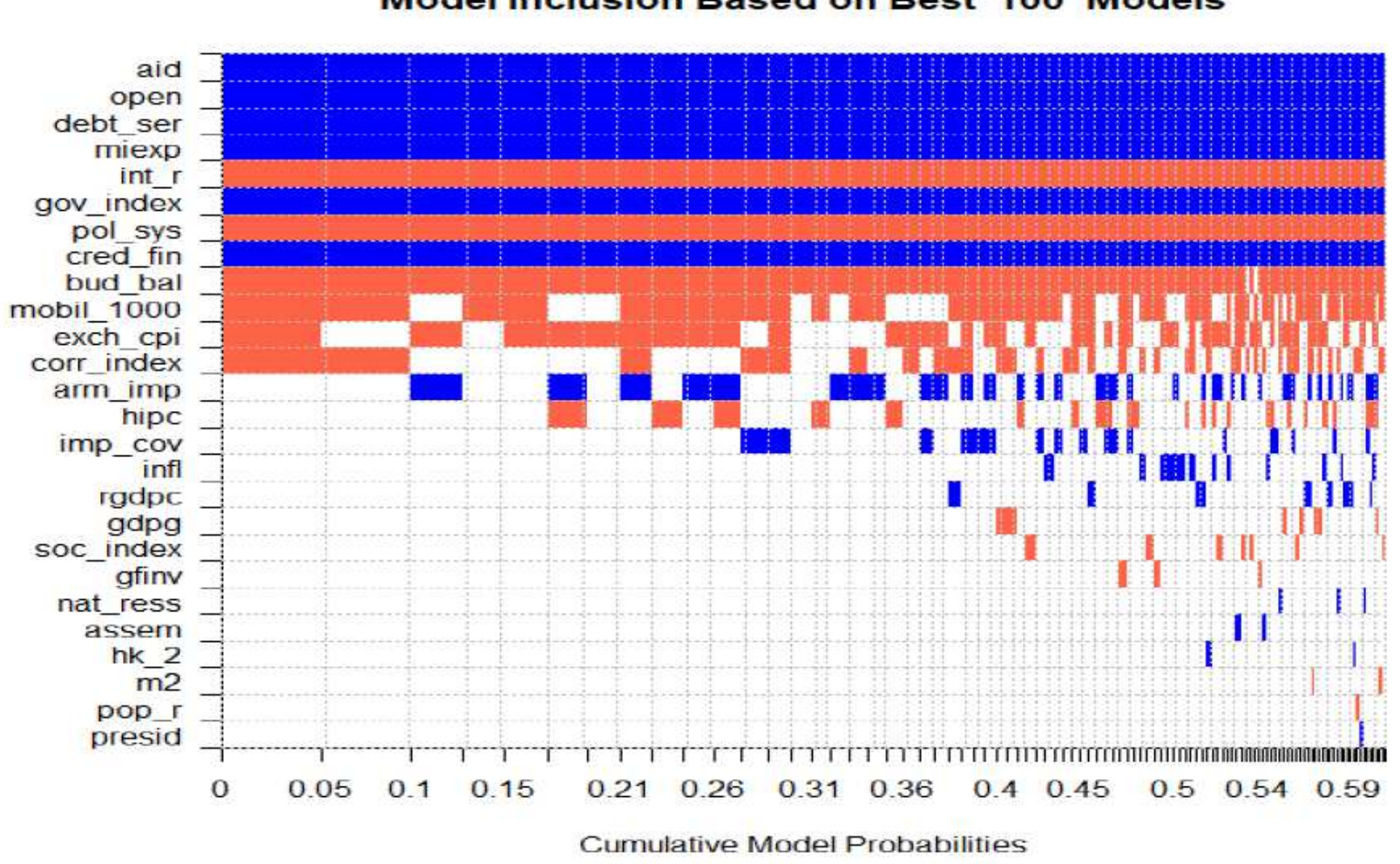

Figure 1.2 : Size and index of models (baseline)

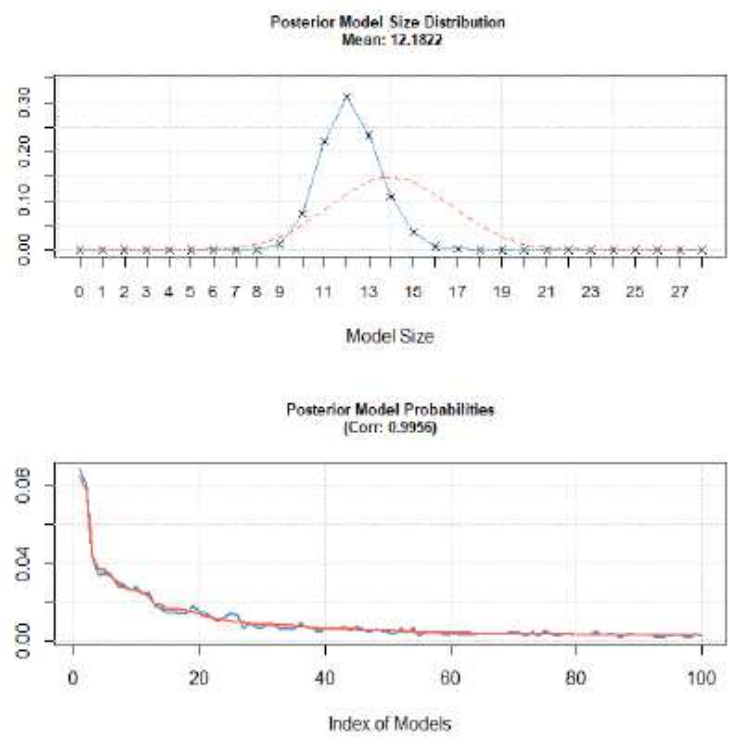

Figure 1.3 : Response variable (baseline)

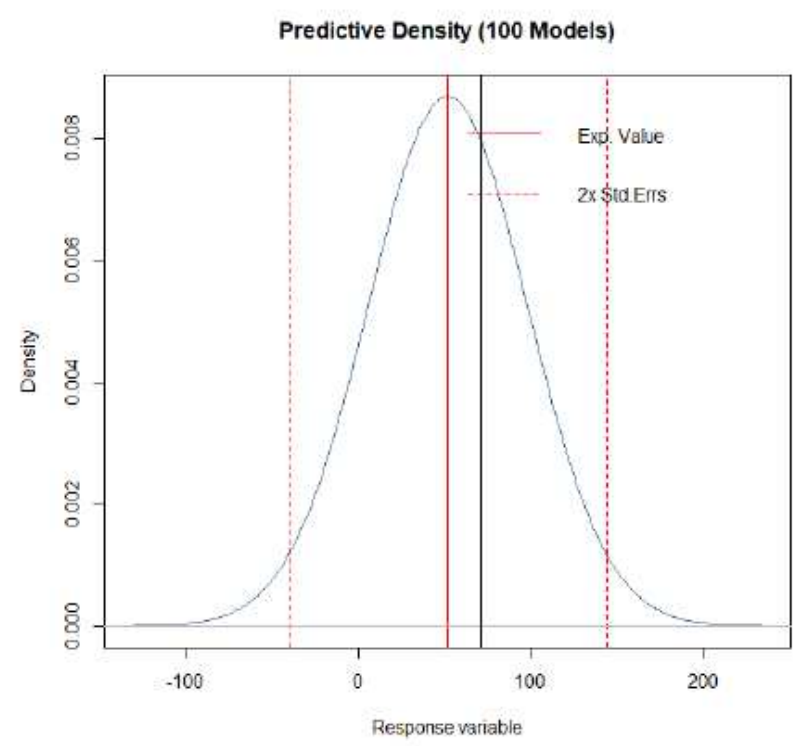

Figure 1 
Figure 2.1 : Cumulative model probabilities (robustness check)

\section{Model Inclusion Based on Best 100 Models}

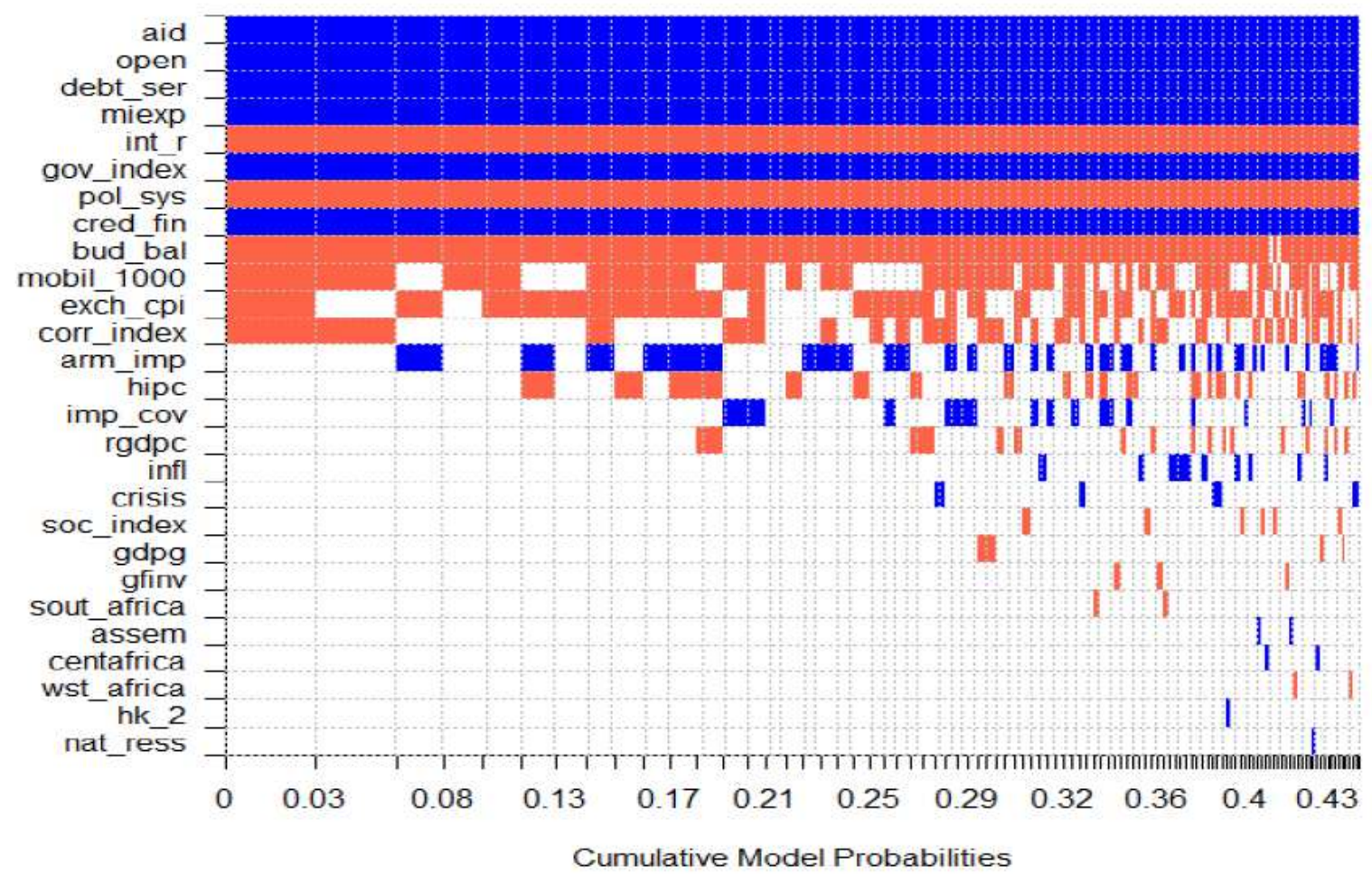

Figure 2.2: Size and index of models (robustness check)
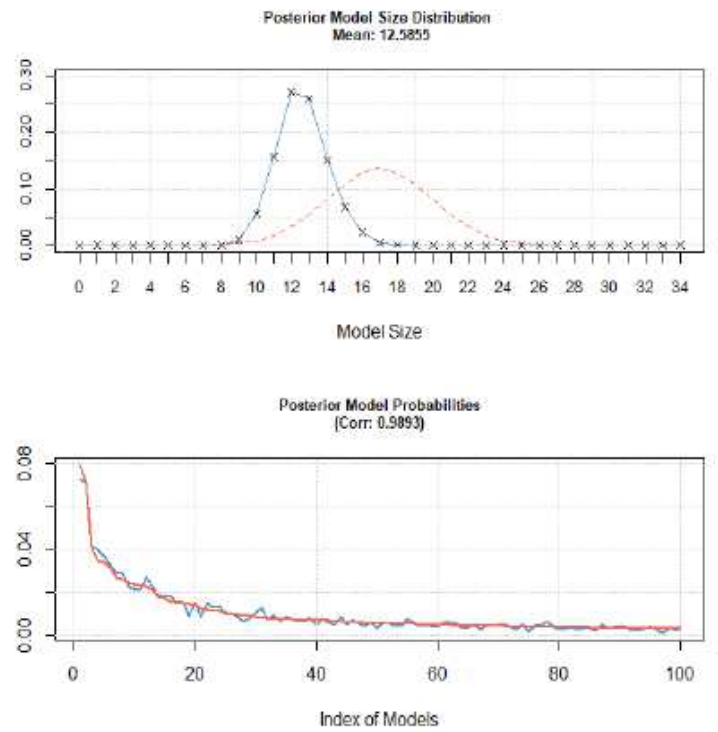

Figure 2.3: Response variable (robustness check)

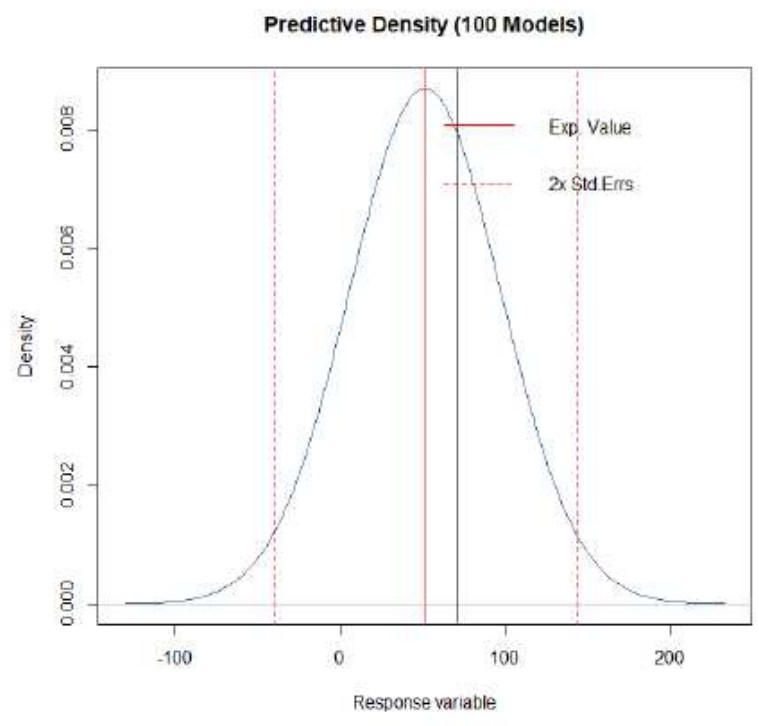

Figure 2 